\title{
Negotiating a new day: parents' contributions to supporting students' school functioning after exposure to trauma
}

This article was published in the following Dove Press journal:

Psychology Research and Behavior Management

22 April 2016

Number of times this article has been viewed

\author{
Eline Grelland Røkholt' \\ Jon-Håkon Schultz ${ }^{2,3}$ \\ Åse Langballe ${ }^{2}$ \\ 'Department of Allied Health, \\ Bereavement Support Center, \\ Akershus University Hospital, \\ Lørenskog, ${ }^{2}$ Norwegian Center for \\ Violence and Traumatic Stress Studies, \\ Oslo, ${ }^{3}$ Department of Education, \\ University of Tromsø, the Arctic \\ University of Norway, Tromsø, \\ Norway
}

\begin{abstract}
Parents are advised to get their children back to school soon after exposure to trauma, so that they may receive social support and restore the supportive structure of everyday life. This study explores parents' experiences of supporting adolescents in regaining school functioning after the July 2011 massacre at Utøya summer camp in Norway. One year after the attack, 87 parents of 63 young people who survived the massacre were interviewed using qualitative interviews. The qualitative data were analyzed using thematic analysis. All parents were actively supportive of their children, and described a demanding process of establishing new routines to make school attendance possible. Most parents described radical changes in their adolescents. The struggle of establishing routines often brought conflict and frustration into the parent-adolescent relationship. Parents were given general advice, but reported being left alone to translate this into action. The first school year after the trauma was described as a frustrating and lonely struggle: their adolescents were largely unable to restore normal daily life and school functioning. In $20 \%$ of the cases, school-home relationships were strained and were reported as a burden because of poor understanding of needs and insufficient educational adaptive measures; a further $20 \%$ reported conflict in school-home relationships, while $50 \%$ were either positive or neutral. The last $10 \%$, enrolled in apprenticeship, dropped out, or started working, instead of finishing school. Implications for supporting parents with traumatized adolescent students are indicated.
\end{abstract}

Keywords: traumatic stress, terrorism, parenting, trauma-informed schools

\section{Introduction}

Parents of children and adolescents exposed to traumatic events are advised to restore normal everyday routines as soon as possible by, for example, encouraging their children to return to school and re-establishing routines and structures. The need for calming and restoring social functioning in order to connect with social support is well documented as a key element in the framework for post-disaster psychosocial intervention. ${ }^{1-4}$ For young people, school is probably the most important community and social arena. The school manual for psychological first aid ${ }^{5}$ notes that the school is typically the first service agency to resume operations after an emergency, becoming a primary source of community support. The manual further argues that teachers can provide much of the intervention needed to stabilize the situation.

Several studies have explored the relationships between family functioning and parenting in connection with child/youth functioning after trauma. Findings indicate that early interventions should focus on supporting previously established parenting
Correspondence: Eline Grelland Røkholt Department of Allied Health, Bereavement Support Center, Akershus University Hospital, Postboks 1000 , 1478 Lørenskog, Norway Tel +4767968 60I Email Eline.Grelland.Rokholt@ahus.no (c) (1) (-) ๑ 2016 Grelland Rokholt et al. This work is published and licensed by Dove Medical Press Limited. The full terms of this license are avaliable at https://www.dovepress. the work you hereby accept the Terms. Non-commercial uses of the work are permitted without any further permission from Dove Medical Press Limited, provided the work is properly attributed. For permission for commercial use of this work, please see paragraphs 4.2 and 5 of our Terms (https://www.dovepress.com/terms.php). 
repertoires. ${ }^{6,7}$ The general advice arising from these studies advocates maintaining normal family life, and stresses the importance and supportive effects of responsive and sensitive parenting styles that provide a secure base for the child. This may include discussing and talking about the trauma with the child and providing empathic listening. ${ }^{6,8-10}$ This advice is often phrased in general terms and is usually intended for parents of young children, rather than for the parents of traumatized adolescents.

Adolescents gradually develop a greater emotional capacity for abstract thinking and self-determination, and in this context, the parental role can be challenged because of rapid changes in the adolescents' psychological and emotional development. Parents have a key role in supporting teenagers who suffer from traumatic stress symptoms, but the latter's need for parental contact and comfort may conflict with their need for independence, leading to ambivalence regarding parental involvement. ${ }^{11,12}$ In the period of transition between childhood and mature adolescence, it can be difficult for parents to consider young people's understanding of, and responsibility for, their own condition. It can also be difficult to discover and understand their need for support because of coping strategies that may include apathy, minimizing symptoms, and joking. Beside these challenges, the developmental period also provides benefits in terms of young people's increased potential to communicate their needs and ask questions to adults they trust. ${ }^{11}$

Posttraumatic stress disorder (PTSD) is one of the most observed reactions among youths after traumatic events, followed by depression and anxiety. ${ }^{13,14}$ Estimates of prevalence vary according to the type and aspects of the disaster. A meta-analysis of 160 studies showed that up to one-third of young people of school age exhibited considerable PTSD symptoms after a disaster. ${ }^{15}$ The first year after exposure was generally the time of peak symptoms, with gradual improvement occurring over time. Nevertheless, many studies show symptoms lingering for months and years for a significant minority of participants.

The Diagnostic and Statistical Manual of Mental Disorders, fifth edition ${ }^{16}$ draws on a strong foundation of research in describing the categories of potential symptoms of traumatic stress: behavioral problems, cognitive implications, somatic distress, and psychological reactions. These symptom clusters, alone or together, may cause short-term disruption of learning capacity or, if symptoms persist, more prolonged learning disabilities. Reduced learning capacity following exposure to traumatic stress should be anticipated.

\section{The Norwegian terrorist attack}

On July 22, 2011, a car bomb was detonated outside the main government building in Oslo, killing eight people and injuring more than 100. The perpetrator then drove to the small island of Utøya, where the youth organization of the Norwegian Labor Party was holding its annual summer camp, attended by 564 participants, with most of them being teenagers. On reaching the island, he engaged in a massacre that lasted for over 1 hour, killing 68 persons, before being captured by the police. Many at the camp were injured; 56 were hospitalized and one died in hospital.

These young people were exposed to a life-threatening situation, experiencing extreme trauma on the small island (only 26 acres). Many saw the terrorist or heard his voice (73.1\%). All heard gunshots; they hid or ran from the terrorist (96.9\%); many saw someone being injured or killed (64.1\%), heard someone being injured or killed (82.6\%), saw dead bodies $(86.7 \%)$; or saw the terrorist pointing a gun at her/ him or realized that he had fired a shot (45.1\%). Furthermore, $74.5 \%$ lost someone very close to them and $96.3 \%$ reported having lost a friend, ${ }^{17}$ indicating a high degree of bereavement and loss. Altogether, 47\% reported clinical levels of PTSD symptoms: $11 \%$ fulfilled the criteria for a full PTSD diagnosis and $36 \%$ for a partial PTSD diagnosis. Posttraumatic stress reactions in survivors were highly significantly associated with general mental health problems, functional impairment, and reduced life satisfaction 4-5 months after the terrorist attack. The psychological state of these young people may have had a considerable impact on their ability to study, work, and maintain a normal social life. ${ }^{17}$

Most of those attending the summer camp were students in upper secondary school or taking other higher education programs. The end of the summer vacation break came 4 weeks after the massacre, and students were expected to be back at school. The Ministry of Education instructed the school leaders through two information letters (5 weeks after and 8 months after the terror attack) to prepare by contacting each survivor during the summer break, in order to plan the return to school in collaboration with the student and the home, and to further individually tailor the adaptations necessary throughout the school year. The Norwegian Directorate of Education and Training also posted detailed information intended for schools on its website ${ }^{18}$ about regulations and pupils' rights to adaptations. The web-based information also included specifications about the necessity of home-school collaboration, as well as guidance to include parents of students above the legal age of 
18. Teachers and school health workers were asked to be proactive and provide the survivors with close follow-up, supporting them to complete their school program. The flexibility provided by the Norwegian Education Act $^{19}$ concerning legal absence and alternative ways of setting grades is also relevant here.

This study explores how parents experienced the process of supporting their adolescent offspring as regards school functioning and home-school relationships in the first school year after being exposed to the traumatic events of the Utøya massacre.

\section{Method}

\section{Participants and procedures}

A total of 531 parents participated in the Utøya study (for further descriptions of the Utøya study, see Dyb et $\mathrm{al}^{17}$ ). All participants gave written informed consent, and the Regional Committee for Medical and Health Research Ethics in Norway approved the study. Those selected for this qualitative study were parents of 17-18 year old adolescents who survived the massacre and who started their second or third year at high school immediately afterwards. This selection criterion of the last 2 years in high school was chosen because students then have final examinations with clear expectations of academic performance. A total of 87 parents of 63 students were individually interviewed. For six pupils, both parents were interviewed. By the time of the interview, five of the students had an apprentice learning internship at a workplace and one student had decided to drop out of school before school started, due to strong stress-related symptoms.

Face-to-face interviews were conducted by health professionals and researchers trained in interviewing traumatized people. The interview started with an open-ended question: "Please, tell me how the past school year was for your daughter/son in terms of good and bad. I am especially thinking in terms of the experiences from July 22, 2011." Interviewers were instructed to provide open follow-up questions such as "Tell me more about that..." and to offer the following keywords when or if the free narrative faltered: academic achievement, social well-being, social-emotional support at school, and worries as a mother/father.

Interviewing was conducted between 14 and 15 months after the massacre. All interviews were audio-taped; the transcription totals 199 pages set in Times New Roman 12 with 1.5 line spacing. Qualitative quotes have been altered as necessary for purposes of anonymity.

The open-ended question aimed to provide an understanding of the informants' subjective experiences. ${ }^{20}$ The qualitative data were inductively coded and categorized using thematic analysis for identifying and reporting patterns within the dataset. ${ }^{21}$ The thematic analysis followed Braun and Clarke's six-phase guide, ${ }^{22}$ in which analysis involves searching within and across the interviews in a recursive process where movement goes back and forth as needed throughout the phases, generating a thematic map. See Figure 1 for a thematic map with hierarchical ordered analytical categories. All three

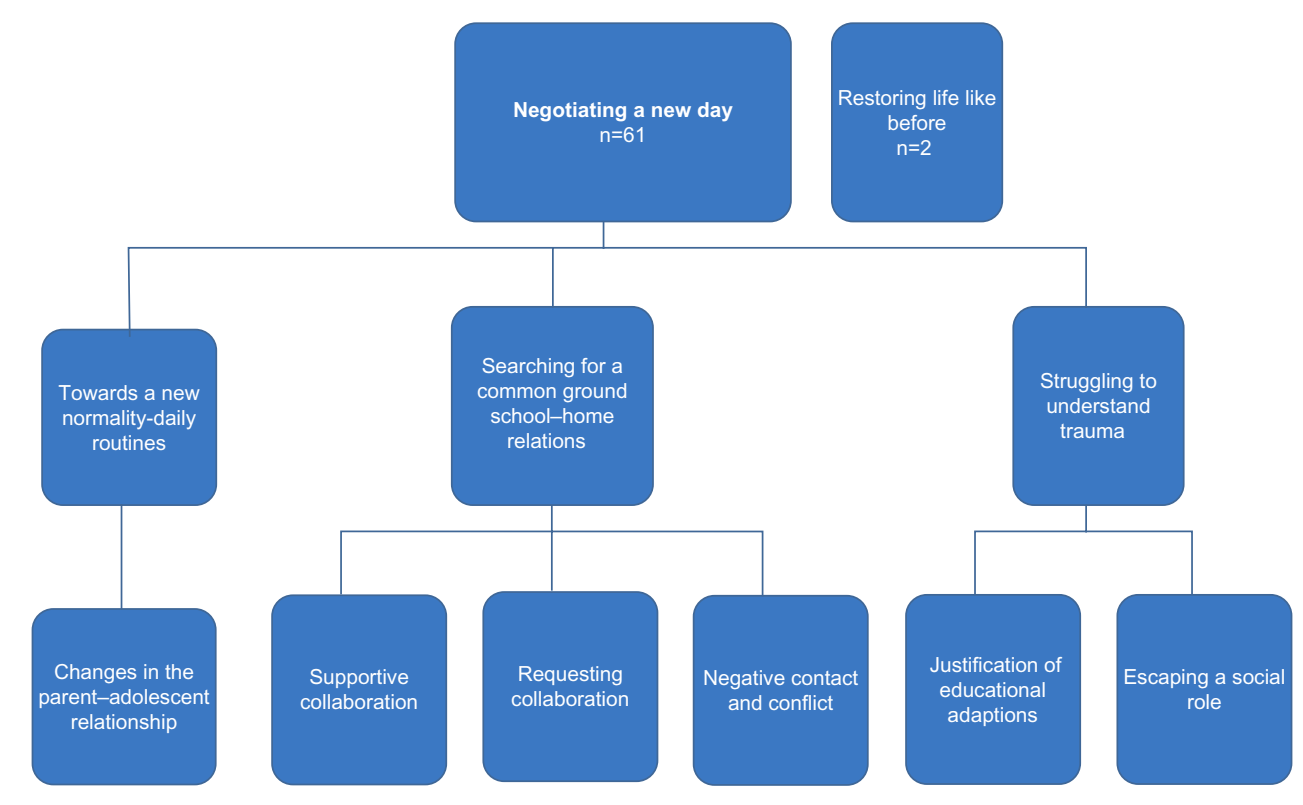

Figure I Analytical categories. 
researchers read the transcripts thoroughly and separately, before discussing and conceptualizing themes identified in the text. When uncertainties arose, the raw data were examined and considered in relation to the proposed categories.

Parents described in various ways their struggle in "restoring" their daily life, when restoring was not a possibility at the time. The concept of "negotiating a new day" emerged as an alternative to "restoring" and was conceptualized as a sensitizing concept. ${ }^{23}$ Negotiating a new day involves finding new ways of coping, adjusting, and altering everyday life. Three main categories were formulated from this concept "toward a new normality" describing home life and leisure time, "searching for common ground" describing school-home collaboration, and "struggling to understand trauma" describing parents' frustrations about understanding the consequences of trauma. The main categories were supplemented with six subcategories.

\section{Results}

The 87 parents often referred to the idea of restoration in describing their initial intention of helping their teenaged son or daughter back to normality in the first weeks and months after the massacre. First, the young person and the family lost their daily routines, and nothing was as it used to be. The adolescents behaved differently, and now had different needs. At the same time, parents found themselves struggling to follow what they perceived as general advice to help their offspring get "back to normal". Gradually, they shifted from attempting to restore performance to re-establishing basic needs. This is the process described in the first main category: toward a new normality.

\section{Toward a new normality}

When describing the school year, most of the parents (75 of 87) spoke of the great effort involved in trying to build completely new functioning daily lives and school routines. Only two parents said that their adolescents had picked up where they left off. For the others, restoration implied changes in their way of life within the first weeks and months following the massacre. They made attempts at somehow patching up life together. As one parent described it:

We attended some meetings where people came and talked about how we had to get a normal everyday routine going as soon as possible. Like, our daughter had to keep attending school all the time, she had to do everything, we had to get going, we had to pretend it did not happen. But that wasn't the point. We have to get an everyday life going, OK, that's fine. We have to get the kids up in the morning, and try to get some kind of meaning through the day. When you have a kid who's not mentally ready at all to learn anything, then you say, go for a walk, walk the dog, just do something.

The above quote is an example of parents describing a perceived "requirement" to restore life as near as possible to how it had been before the trauma. It is somewhat unclear exactly who provided such advice to parents, in what context, and how detailed it was. Nevertheless, a commonly reported piece of advice was to "get back to normal everyday routines" and for the adolescents was to "get back to school". Many of the interviewees opposed this type of general advice, saying it did not match their new reality or the young people's needs. At this point, many parents perceived their adolescent as having an actual functioning level equivalent to a young child's needs in responding to the challenges of sleeping, eating, and finding some sort of daily structure. The goal of "restoring" family habits and school activity was seen as out of reach. Our interviewees described how they came to realize they would not be able to follow the advice about restoring the situation and getting back to normal, only weeks after the massacre, and they adjusted to that situation. They discarded the performance-oriented perspective, and shifted to focus on helping and supporting their adolescent in just getting through the day: "surviving the day". The main goals for parents were defined as getting the adolescent up in the morning and having some kind of meaningful task for the adolescent to do, with parents having few or no expectations as to performance.

I told him that I don't care about grades. Just that you get up in the morning and attend school, that you make it through the day - that's all I want right now.

All parents expressed a clear motivation and engagement to actively support school attendance. They described several challenges concerning their parental role, what measures to administer, and how to determine what the needs were. They felt a great responsibility to support their offspring, and expressed considerable uncertainty as to whether they were overprotecting or demanding too much. Parents commonly blamed themselves for not doing enough - without knowing what they actually should have done or thinking they should have done differently.

I blame myself, it is a constant balance between if I should interfere, or respect that she needs to rebel against her mother. What is actually "good care" now? I think it is really difficult to know. 
At the same time, apart from worrying about their adolescent's well-being, parents struggled to see the massacre as the actual cause of the problems. They felt uncertain as to whether the many different problems their adolescents were having, in everyday life and school functioning were, in fact, linked to the events at Utøya.

Sometimes I wonder if it would be wise if he could just get a grip on himself, but at the same time I don't know if he is able to. Would it work? I don't know. And what really explains the problems he's experiencing now?

He dropped out of school after what happened [on Utøya]. Maybe that was the direct cause or maybe it was some sort of combination of him being tired of school, but it might have been the decisive factor that led him to leave school.

\section{Changes in parent-adolescent relationship}

Parents reported changes and challenges concerning the parental role that also affected the parent-adolescent relationship, with conflict and frustration most frequently mentioned. About $60 \%$ of the parents mentioned major changes in their adolescents' everyday life regarding, for example, living arrangements, regression of age-appropriate independence, sleep-related difficulties, and problems in social relations.

She was going to rent a room with a friend and had been looking forward to that. We helped her to move, but then she couldn't go through with it. After two nights she moved back home again.

She had a room downstairs, but was too afraid to sleep there. We had to move all her stuff up to her old room next to ours.

Parents adopted a pragmatic approach, with various efforts at scaffolding the practical support necessary to meet the running basic needs. There were practical measures, such as making sure their adolescent got up in the morning, creating a balance between day and night time. They provided food to eat, something meaningful to do during the day, driving the adolescent to his or her activities, staying up with their sleepless adolescent during the night, they contributed to contact with friends and helped with homework. These new routines were established through parent's ongoing involvement and continuous presence, assisting and compensating for their adolescent's lack of daily functioning.

For most parents, these new measures did not take the form of a new daily routine that fell naturally into the parental role; instead, they experienced it as an ongoing struggle of trying to support their adolescent and create new functional routines.

The biggest problem was to get her going, get her out of bed and off to school, while she kept saying that she didn't want to go to school.

It was a lot of headache and stomachache and explanations about classes starting later, like substitute excuses to stay home from school. We decided to accept this and didn't make any fuss about it, but sometimes we just said: Really, again? What is it this time? What is this about? But I never felt that he really let us into his thoughts and feelings. It was never a nice dialog together where he would talk with his mom about his difficulties. Oh no, not at all.

The ongoing struggle changed and brought conflict and frustration into the parent-adolescent relationship. In many cases, this turned into a "war" between the two sides and also put a considerable strain on the parents.

It was a bit intense, for me as a mother to force her to get up [...]. It was quite brutal, as brutal as I've ever been, but it did result in her actually starting to do some exercise and be more social.

It hasn't been nice, lots of conflict at home. There were horrible starts to the day, and his brother has witnessed the warfare involved in getting him up. We simply wouldn't give in. Every morning we (parents) would look at each other: Is it your turn or mine today? [...] I think it is positive to maintain a sort of routine and that has been a goal for us. You could say we forced him into a routine.

\section{Searching for a common ground}

In the second main category "searching for common ground" focusing on school-home collaboration, the parents often spoke of how major changes in everyday life functioning, in turn, affected their adolescent's school attendance and performance, both at school start and throughout the first school year. The difficulties resulted in a great need for collaboration between parents, adolescent, and school. One father explained:

We had a good agreement with the school [...]. But the school, psychologists, families, and doctors have to stay in close contact, even daily, discussing how the day has been.

The changes called for new and extended school-home collaboration, as new needs for adjustments and support emerged. The parents reported a considerable need for supportive cooperation between school and home, such as 
contact with the teacher about the adolescent's well-being, arrangements on possible adjustments about workload, deadlines, changes in subjects, and about absence.

Only seven parents said that their adolescent's performance level stayed the same; five of these explained that it involved compensating by radically increasing the work effort to achieve the same level of academic achievement. In two cases, the academic functioning stayed the same; they carried on where they had left off. For the remaining 56 students (90\%), however, the parents reported considerable changes in school performance that required extensive support from home. About 10\%, enrolled in apprenticeship, dropped out or started working, instead of finishing school. Parents' experiences of home-school collaboration include the subcategories of supportive collaboration, requesting collaboration, and negative contact and conflict. The five students enrolled in apprenticeships and the one working are not included in the following social support categories.

\section{Supportive collaboration}

Nearly $50 \%$ of the parents spoke of neutral or positive experiences with school-home collaboration, with the school being supportive and understanding, initiating contact with the students and parents, or offering some measures for adapting. Parents viewed such initiatives as a measure of goodwill, and of acknowledging the situation and the parents' concerns.

They support us and our kids in every way. If they hadn't helped out, we would have been in big trouble, for sure.

Most of the positive descriptions made no mention of educational measures, or the outcome. Parents remained positive about the school's attitude and goodwill efforts, even though academic work deteriorated.

I kept in touch with the teacher by email and phone. She told me about her impressions and that my son really wants to do well, but he just can't seem to manage.

In their relationships with the schools, parents tried to provide and also obtain information about their adolescents' progress and difficulties. Where school-home relationships had been established, parents often spoke of attending meetings and actively taking part in discussing measures and adjustments.

\section{Requesting collaboration}

About $20 \%$ of the parents reported they had to initiate or pressure the school into collaboration concerning educational adaptive measures they felt were necessary.
I believe that if the school hadn't come under so much pressure from the psychiatric team and others about the school's duty to be more understanding and to make adaptations available, my daughter wouldn't have managed that school year. It became a completely different year for her.

Some parents noted that when contact with the school was finally established, there was support and effective adaptive measures were offered. Others, however, felt they were left with inadequate support, even after initiating collaboration.

He didn't sleep at night and couldn't get up in the morning. Sometimes he just stayed at home. I tried to contact all his teachers and asked them to talk to him, let him know that they would like to see him in class. Support him, so that we could get him going. But a teacher has many things to do, not just one student, so it didn't happen.

I asked the school what measures they could offer, but they had no ideas. I had a meeting with them, and they only suggested some examination papers for him to practice on. I knew that wouldn't do the trick.

This lack of initiative for collaboration and random contact was perceived as lack of interest from the school. Parents in this subcategory also questioned the role of the teachers, wondering whether they were sufficiently prepared for teaching traumatized pupils.

She was absent from school a lot. She was very tired, and was given a room at school where she could be alone. She was very irritated and critical of her teachers and thought everything was difficult. We eventually had meetings with the school about adjustments. But I thought it was difficult to know where to draw the line. It seemed that the teachers found it at least equally difficult.

After heavy pressure on the school, they finally became fairly generous with adjustments. [...] Still, I think they could have relieved him of more responsibility. We should not have to go looking for all the solutions. Somebody could have asked him or us. And somehow they reach a level of a grade in a subject, and surely they don't need six or seven tests to prove the same point when his brain is full. It's all a combination of lack of understanding and a fear of applying existing school legislation rules.

\section{Negative contact and conflict}

When adequate school-home collaboration was lacking, parents tried to negotiate their adolescents' rights, taking the matter 
further in the system. One father spoke of how conflict with a teacher escalated due to lack of understanding and conflict between the teacher and his daughter; she then applied to change teacher. The conflict resolution meeting ended with his daughter feeling pressured to continue with the same teacher. The father objected to this, but was met with what he experienced as an unbending attitude from the school. He filed a complaint to the county office, at the same time fearing reprisals on his daughter from the school. About $20 \%$ of the parents reported types of negative contact and conflict with schools.

She had a conflict with her gym teacher. She tried to explain why she couldn't cope, and the teacher just replied "but that's your problem".

I remember in the beginning, his teacher instructed him to run a certain distance. Like a mile or something, "run as fast as you possibly can" the teacher said, and that was in the beginning of the school year. He replied, "I've already had to run for my life, I'm done with running as fast as I can". The teacher kept on insisting.

Parents perceived the lack of understanding and absence of flexibility in the school setting as a hopeless situation where they had to fight for credibility. This fight often turned into a conflict when they felt they were not met with understanding.

Even though my daughter talked about the need for flexibility as regards to adaptations, even though the counselor and school nurse backed her up, it had no effect on the school administration. Several other students felt the same - they were not taken seriously. It's understandable that they dropped out of school. No wonder when the school doesn't even try to keep them there.

There are many reasons for being absent from school, and she has a valid reason in my mind. So it's a fight for credibility.

Parents described how the burden of lack of understanding and negative contact represented further unnecessary pressures in an already strained situation, an additional battle they had to take on at an already difficult time:

This year has been very hard, maybe mostly because we had to fight the school to achieve some little extra flexibility.

\section{Struggling to understand trauma}

In the last main category "struggling to understand trauma", parents and school alike appeared to have an unclear understanding of the possible consequences of traumatic stress. The major challenges were related to how to communicate about needs and what to do about the problems. How long will the problems persist? And how long should adjustments be offered? Even within the first year, the more time that had passed since the massacre, the more blurred seemed the connection between symptoms of traumatic stress and the traumatic event. This also gave rise to questions about social roles after trauma, and to what extent some might use the massacre as an excuse for laziness and poor performance. This led to the following two subcategories of justification of adaptations and escaping a social role.

\section{Justification of educational adaptations}

Parents reported that their adolescents' school performance before the massacre was often used as a baseline for justification of various adaptive measures. Students whom teachers had experienced as high performers before the massacre were automatically entitled to adaptive measures and extra support. For the high achievers, there could be no doubt that their sudden lack of academic achievement was something new, obviously linked to the massacre.

She had to drop one subject because things got too hard. It was all because the teacher didn't understand and hadn't known her from before. We noticed a great difference: the teachers who'd known her realize she's not sloppy, they know what she is good for. The others don't.

However, for those with a previous history of not being so good at schoolwork, new problems were added, and they remained low achievers. The boy referred to in the quote below had failed his final exams the year before the massacre, and was taking the same school year over again:

The teacher was always telling my son, "you've already been here [in this grade], so you must know this stuff by now". But there is a reason why he failed the first time. When he couldn't get it this year, either he felt burdened by the teacher saying: "Now you need to pay attention [...]. You don't pay attention [...]. Oh, haven't you got it yet?" All the time it was negative. He dropped a couple of subjects because he just couldn't cope with all the nagging.

Another recurrent question among parents was how long the problems with school functioning would last - when would their offspring be able to regain their lost learning capacity?

The hard part was that we had no idea about the consequences; we'd thought everything would work out after a 
while, that he'd be able to concentrate again. We had an agreement with the school about some adjustments in math.

We thought that would be enough. But it wasn't.

Most of the parents reported meeting expectations directly or indirectly for about 3-6 months after the massacre; then it was time to "leave it all behind" and "not only keep focusing on the problems". The belief that it would all go away and that the adolescent should move on was frequently communicated at school, sometimes explicitly:

He told us that his teacher had said to him, "Now you have to leave Utøya behind you." As if his problems were because of laziness. And this was just months after 22/7. I was furious and arranged a meeting with the principal and everybody involved.

We had a meeting with the local crisis team, with a psychologist present. The psychologist sat with his arms crossed and said "Oh well, it probably will pass, you see". That's what he said, nothing more.

Parents reported that the adaptive measures provided at school were suddenly withdrawn and terminated, apparently without any consideration of whether they were needed. The argument was that time had passed and the massacre now belonged to the past.

We had such a close follow-up from school. They did very well. The teacher attended the national course for teachers and did an incredibly good job. But then, they just dropped everything completely - because that school year was over.

And this year it's nothing.

In contrast to such a sudden withdrawal of adaptive measures, other parents in the supportive collaboration category experienced more regular meetings with clearer communication on the current educational situation, evaluations of adaptive measures, and thoughts on future planning. Some parents had an agreement that educational measures should be removed, but if they were needed again, they would be reinstalled without hesitation.

\section{Escaping a social role}

Parents in this subcategory described how their adolescents went to great lengths to avoid any type of excuse connected to the traumatic event. They referred to their offspring being afraid of being suspected of using the massacre to gain privileges at school, such as less homework, "easier exams", or being excused for coming late to classes and having days off.
Not many teachers asked how he felt in school. They just kept on. He was particularly careful not to use the "Utøya card". He didn't dare to say: "I have needs because I have problems from Utøya". I tried to push him to say it, but he didn't want to use it. They [teachers] were quite hard on him when he didn't do well in school.

He got mighty irritated because he wanted to change one class. They go with different groups depending on the subject. So he wanted to change to where he could be with his friend. Then the teacher said, "No, we can't allow that. But if you manage to connect it to July 22, we will allow it". This made him angry: "I am not going to play the Utøya card to get any kinds of advantages", he said. He felt the teacher didn’t understand anything.

There are several examples in the material where parents observed their adolescents declining any exceptions at school if these were "officially" linked to the massacre. Parents thought the exceptions had become visible signs that linked the student to a stigma of being an "Utøya survivor who needs all sorts of special exceptions".

A significant number of parents expressed doubt as to whether their offspring had tried to take advantage of the situation, using the traumatic event to obtain favorable exceptions at school. Parents reported uncertainty as to whether the expressed needs were real, and whether they should accept or challenge them. Parents experienced a dilemma: should they support the adolescent who claimed that she/he needed more special measures at school, or would the right approach be to challenge this perspective? This quote illustrates this:

It has become a sort of easy way out. I threaten her and tell her that if you don't do this [...] it clearly becomes an easy way out if her actions don't have consequences. Now it is down to your will power, I told her. I know there are days you cannot cope, but that's the way it is with everyone. It really exhausts me [...]. But I don't know: how far can you push, really?

\section{Discussion}

Most parents described radical changes in their adolescent and a demanding process of establishing new routines after the Utøya massacre. The process of establishing new routines often brought conflict and frustration into the parentadolescent relationship.

\section{Toward a new normality}

For nearly all of the 87 parents interviewed, the process of trying to restore the normality of everyday life for their 
daughters or sons meant having to establish functioning routines differently from their previous everyday routines prior to the massacre. "Restoring" had become not a process of returning to the original routine, but of constructing a new, functional routine now as "the trauma has changed everything".

A new structure for everyday life had to be established, and by 17 or 18 - the age group in our study - most adolescents can be expected to have a high degree of self-sufficiency and independence in their lifestyles. The Utøya trauma disrupted many in their ability to follow everyday life routines and changed their need for parental support. The observed change can be described as a functional regression, where behavior is no longer age appropriate.

The process of establishing a functioning everyday life routine entailed various complex parental dilemmas. Parents struggled with what choices to make, what battles to fight, and asked themselves, "What is the best care now?" Parents were aware of the importance of getting back to school and regaining an ordinary life, but were not prepared for what this would actually mean. The process of negotiating a new day was an unexpected situation. At the same time, deterioration in the level of everyday life functioning seemed to be severely under-communicated between parents and the school, despite the fact that the outcome of negotiating new everyday routines appeared to be a precondition for further school functioning. Basic everyday routines of sleeping and eating needed to be at a minimal functional level before learning could be dealt with.

Only two students were reported as continuing at their previous level of school functioning. Five students achieved the same results by enforcing on themselves a highly increased work effort. For the remaining 56 students, their parents reported a moderate to severe drop in school functioning throughout the first school year after the Utøya massacre. These findings document a considerable impact in school functioning for that first year. There is evidence that posttraumatic stress symptoms are associated with distinct brain dysfunction patterns and cognitive impairments. Studies have shown that verbal memory impairment is the most consistent cognitive impairment. In addition, studies indicate that basic attention capacities seem to be preserved, but complex attention and executive skills - such as inhibiting inaccurate responses and filtering irrelevant information - are impaired in patients with PTSD. ${ }^{24-26}$ In a study on survivors from the Utøya massacre $(\mathrm{N}=24)$, long-lasting severe symptoms of stress were found in one-third of the survivors 2 years following the traumatic event. However, participants' subjective perception of their cognitive difficulties and objective measures of these did not significantly correlate. ${ }^{27}$ These findings indicate that the subjective feeling of cognitive deterioration does not necessarily reflect the cognitive performance.

\section{Barriers to a new normality}

Parents who reported neutral or positive experiences with support from the school (nearly 50\%) generally felt that the schools lacked efficient knowledge on how to deal with students' school functioning. The parents perceived the school had nothing to offer but kindness, leaving educational adaptive measures given seemingly often by chance. Several studies have indicated that the teacher's role toward traumaexposed students is unclear. Teachers report that they are uncertain of what to do and whether it is within the role of teaching to engage in measures for dealing with the mental health of trauma-exposed students. ${ }^{9,28,29}$ Parents in our study confirm this uncertainty on the part of teachers and schools in understanding the situation of traumatized students and their role in dealing with the educational consequences of traumatic stress. As the parents had already shifted their parental goal from supporting their adolescent in making "good school achievements" to a survival mode of support by merely showing up at school, it implies that many parents came to lower expectations and just accept that the school could not offer any effective adaptive measures. According to the Norwegian Education Act, ${ }^{19}$ schools have the responsibility for providing adaptive measures and revising goals for learning when the student cannot benefit from ordinary teaching methods.

Numerous studies have confirmed the strong relationship between lack of social support and negative mental health in the wake of adversities. A meta-analysis has shown that lack of social support is among the most prominent risk factors for posttraumatic stress reactions following traumatic events. ${ }^{3,4}$ Symptom severity and recovery appear to be related to social support. ${ }^{30}$ When parents explicitly voiced their expectations about teachers' ability to deal with pedagogic challenges, about $20 \%$ of the parents ended up in strained collaboration and $20 \%$ ended in a clear state of conflict with the school, and thus, $40 \%$ of the parents reported a lack of social support and, in some cases, presented clear examples of negative social support from the school. Importance of considering whether potential supporters may actually act in an undermining fashion that can prove destructive is stressed by Hobfoll et al. ${ }^{2}$ This may involve displaying unrealistic expectations regarding recovery, minimizing problems or needs, invalidating messages, and resisting providing necessary assistance due 
to lack of understanding. Negative social support is a strong correlate of long-term posttrauma distress.

\section{Relying on time as a healing factor}

The empirical findings in this study are in line with research documenting a temporary cognitive impairment following traumatic stress, but the parents and teachers alike were surprised that the cognitive impairment should last throughout the first school year. Unable to recognize poor functioning in school as a symptom of traumatic stress, they kept searching for other explanations. In some cases, the negative effects were attributed to traumatic stress, as most of these students had a clear previous history of excellent school performances. By contrast, the parents and teachers of those who had previously been low achievers appeared to be less likely to acknowledge the change into even poorer performance as a consequence of a traumatic stress reaction.

Educational adaptive measures appear to have been offered more often if the student showed marked changes and if the school performance had been stable and good prior to the Utøya events. Questioning the cause-and-effect relationship between current learning difficulties and the consequences of trauma, primarily for students who had low school performance previously, would indicate that the current difficulties did not stand out from the previous problems. Likewise, it appeared that new problems were not "real enough", or that willingness or laziness could be separated from the consequences of trauma. When it was hard to distinguish between pre-existing and new problems, parents and teachers (as perceived by the parents) appeared less likely to understand that adaptive measures were needed. From an educational perspective, however, these adolescents were probably the most in need of understanding and support to compensate for the learning disabilities resulting from temporary cognitive impairment caused by the traumatic event.

In searching for the causes of changed behavior outside the paradigm of traumatic stress, parents and teachers (as perceived by the parents) frequently viewed the problems within a moral framework: judging whether special adjustment measures and benefits were justified, locating the problem within the student and not the school. Also implied are social roles that see adolescents as lazy, demanding, and underachievers. There seems to be a rather widespread view that young people will often misuse the sympathy or adjustments concerning their situation, presenting themselves as victims. This reflects the stereotypes and myths about selfishness and reluctance to take responsibility ${ }^{31}$ and can lead to an overestimation of actual misuse. The concept of "the Utøya card" conjoins several social roles concerning the young person's needs and getting a "free entry card" for special treatment. It plays on the possibility of getting special treatment simply because one is an Utøya survivor, regardless of whether such treatment is really needed: being given these rights somehow sets the recipient apart from or above everyone else.

Such questioning of time, and the expectations that the new problems would disappear in a few months, can be viewed with a parallel reference to traditional grief theory and earlier understandings of grief: the goal was being able to forget, leaving behind, breaking with or being finished with the pain within a timeframe of a few months. This stems from Freud, ${ }^{32}$ Lindeman, ${ }^{33}$ and other early grief theorists who held that the process of bereavement developed in separate stages. This stands in contrast to a newer grief theory that sees bereavement as a process of oscillation between focusing on loss and focusing on restoration over a long period of time. ${ }^{34,35}$ The amount of time passed often seems to be set as a single qualifying measurement, which has as a parallel the adage "time heals all wounds". Thus, time alone sets the premises of expected symptoms. At some point, time will "run out" and problems should end, but this may contrast strongly with real experience, as it did for the parents in this study.

Parents felt being left alone in a frustrating struggle to understand the consequences of the trauma. They found it difficult to know if the problems were real or were excuses. Without a functional framework of knowledge and vocabulary connected to traumatic stress, parents and others might look elsewhere in seeking to attribute the causes of change in behavior. It was striking how few trauma-informed explanations came up when parents described the reduced functioning of their adolescents, or in their discussions with the school. Often, the description was placed within a moral framework: are they telling the truth, or are they taking advantage? Within this framework, understanding of changes in behavior is framed largely within a judgmental and ethical perspective - the adolescent is either lying or telling the truth, making special educational adaptive measures either deserved or not.

Understanding the consequences of trauma requires being able to understand the general concept of traumatic stress. Psychoeducation can provide such a basic understanding, offering a better basis for predictability and a more precise vocabulary for grasping observed changes. The role of psychoeducation is to normalize reactions and help individuals see their reactions as understandable and expected. Furthermore, the process of normalizing and 
validating expectable and intense emotional states, and promoting survivors' capacities to tolerate and regulate them, are important goals at all levels of post-disaster intervention. ${ }^{2,36}$ Theoretical knowledge enhances our capacity to see and understand. The more theoretical knowledge we have, the more flexible our understanding becomes. ${ }^{37}$ This study has clearly shown that parents are struggling to try to comprehend the cause and effect of their adolescents' changed behavior after the traumatic events in Utøya, and that poor understanding of traumatic stress appears to have led to inadequate expectations concerning how long the difficulties would persist.

\section{Strengths and limitations of the study}

The study provided unique data on how parents perceived the process of supporting their adolescents' school functioning when exposed to traumatic stress after terror. The study concerned a high number of adolescents, 63 students aged 17-18, who had all experienced extreme exposure to trauma and were all attending the same two levels of upper secondary school across the country. This allowed us to explore 87 interviews of parents who experienced a high degree of comparable conditions.

However, the study was challenged by limitations of the interview context. The 87 interviews were conducted by 35 different interviewers, with differing interviewing styles. The interview was conducted at the very beginning of a 60-90 minute standardized questionnaire that might have provided a somewhat hasty situation with insufficient time for follow-up questions and elaboration. Furthermore, this study explored the subjective experiences of the parents - not the views of the adolescents themselves, their teachers, or the quality of adaptation measures offered.

\section{Conclusion}

The study investigated how parents experienced the process of supporting adolescents in getting back to regular school functioning in the first year after being exposed to traumatic stress after terror.

The parents interviewed were all actively and substantially involved in trying to support their adolescents in this difficult time. They reported receiving advice aimed at getting the young person "back to normal" and "back to school" as soon as possible, but said that they felt left to their own devices in translating advice into practical action. General advice of getting back to "normal" appeared not realistic, so parents had to redefine their approach and aims. Establishing functional routine meant a time-consuming and demanding process of negotiating new, functional routines in a new normality that could make school attendance possible. From a parental guidance perspective, this finding indicates this being an important point to address directly, in order to prevent feelings of insufficiency in adolescents and parents alike.

According to parents' reports, both teachers and parents frequently struggled with similar challenges concerning uncertainty as to the consequences of trauma: are the observed changes a result of experiencing the massacre on Utøya? The parents lacked adequate trauma-informed explanations that could help and guide them in understanding the changes in their traumatized adolescents, in daily life and in school performance, leaving them to search for explanations elsewhere.

These parents were left with uncertainty and the feeling that any special measures offered were too few and were removed too early. At the same time, they continued their efforts and struggles to support their offspring at home to enable school attendance. From a collaborative perspective, the parents remained largely an unused resource for the schools in supporting students' academic functioning. The schools should provide a proactive outreach, inviting parents to find common ground for a strong collaboration that should last more than 1 year.

For most of the parents in this study, the school seemed to have been unable to provide efficient helpful advice or to enlighten parents on how to understand and act concerning their adolescents' impaired school performance. Vital communication about the relationships between everyday life functioning difficulties, school attendance, and academic performance was absent in home-school collaboration. About $40 \%$ of the parents reported strained school-home relationships, as well as a lack of understanding and sufficient educational adaptations by the school. These findings are not compatible with what the literature describes as "trauma-informed support" - which in turn indicates that a substantial number of the 63 students did not meet a trauma-informed school system. Importantly, parents and teachers alike would benefit from proper psychoeducation, with practical descriptions and explanations of reactions to trauma and educational consequences. In the Norwegian school system, this support could be delivered by the educational and psychological service.

\section{Implications}

Implications for school policy development and response procedures after trauma can be suggested. First, there seems to be a high need for ongoing interdisciplinary collaboration 
between school, health care, and students and their parents during the first year after trauma. This includes psychoeducation and possible educational adaptations. Second, in school-home collaboration, there should be an ongoing communication with the focus on possible deterioration in daily function. Third, parents need professional advice concerning dilemmas that arise in the process of determining best care. Schools should establish routines on including parents of traumatized students in collaboration both immediately and mid- to long term after the traumatic event. More research is needed on how to understand adolescents' social and educational experiences in the school arena in the aftermath of trauma.

\section{Acknowledgments}

The Norwegian Ministry of Education and Research has financially supported the study. We thank the following researchers for valuable comments: Kari E Bugge, Gertrud S Hafstad, Tonje Holt, Dag Skarstein, and Grete Dyb, project leader of the Utøya study, and all the parents who generously shared their stories.

\section{Disclosure}

The authors report no conflicts of interest in this work.

\section{References}

1. Herman JL. Trauma and Recovery. The Aftermath of Violence - From Domestic Abuse to Political Terror. New York: Basic Books; 1997.

2. Hobfoll SE, Watson P, Bell CC, et al. Five essential elements of immediate and mid-term mass trauma intervention: Empirical evidence. Psychiatry. 2007;70(4):283-315.

3. Brewin CR, Andrews B, Valentine JD. Meta-analysis of risk factors for posttraumatic stress disorder in trauma-exposed adults. J Consult Clin Psychol. 2000;68(5):748-766.

4. Ozer EJ, Best SR, Lipsey TL, Weiss DS. Predictors of posttraumatic stress disorder and symptoms in adults: A meta-analysis. Psychol Bull. 2003;129(1):52-73.

5. Brymer M, Jacobs A, Layne C, et al. Psychological First Aid - Field Operations Guide, 2nd ed. Los Angeles, CA: National Child Traumatic Stress Network and National Center for PTSD; 2013.

6. Hafstad GS, Gil-Rivas V, Kilmer RP, Raeder S. Parental adjustment, family functioning, and posttraumatic growth among Norwegian children and adolescents following a natural disaster. Am J Orthopsychiatry. 2010;80(2):248-257.

7. Hafstad G, Haavind H, Jensen TK. Parenting after a natural disaster: A qualitative study of Norwegian families surviving the 2004 tsunami in Southeast Asia. J Child Fam Stud. 2012;21(2):293-302.

8. Sheeringa MS, Zeanah CM. A relational perspective on PTSD in early childhood. J Traum Stress. 2001;4(4);799-815.

9. Alisic E. Teachers' perspectives on providing support to children after trauma: A qualitative study. Sch Psychol Q. 2012;27(1):51-59.

10. Ainsworth MDS, Blehar MC, Walters E, Wall S. Patterns of Attachment: A Psychological Study of the Strange Situation. Hillsdale, NJ: Lawrence Erlbaum; 1978.

11. Horowitz L, Kassam-Adams N, Bergstein J. Mental health aspects of emergency medical services for children: Summary of consensus conference. J Pediatr Psychol. 2001;26(8):491-502.
12. Lattanzi-Licht M. Helping families with adolescents cope with loss. In: Corr CA, Balk D, editors. Handbook of Adolescent Death and Bereavement. New York, NY: Springer Publishing Company; 1996:219-234.

13. Kliethermes M, Wamser R. Adolescents with complex trauma. In: Cohen JA, Mannariono AP, Deblinger E, editors. Trauma-Focused CBT for Children and Adolescents. New York, NY: Guildford Press; 2012:175-196.

14. Prinstein MJ, La Greca AM, Vernberg EM, Silverman WK. Children's coping assistance: how parents, teachers, and friends help children cope after a natural disaster. J Clin Child Psychol. 1996;25(4):463-475.

15. Norris FH, Friedman MJ, Watson PJ, Byrne CM, Diaz E, Kaniasty K. 60,000 disaster victims speak: Part I. An empirical review of the empirical literature, 1981-2001. Psychiatry. 2002;65(3):207-239.

16. American Psychiatric Association. Diagnostic and Statistical Manual of Mental Disorders. 5th ed. Washington, DC: 2013.

17. Dyb G, Jensen TK, Nygaard E, et al. Post-traumatic stress reactions in survivors of the 2011 massacre on Utøya Island, Norway. BJPsych. 2014;205(5):361-367.

18. Norwegian Directorate for Education and Training. Available from: http://www.udir.no/Laringsmiljo/Beredskap-og-krisehandtering/. Accessed June 29, 2015.

19. Ministry of Education and Research, Forskrift til opplæringslova. [Norwegian Education Act] 2006.

20. Brinkmann S, Kvale S. InterViews: Learning the Craft of Qualitative Research Interviewing. 3rd ed. Los Angeles, CA: Sage; 2015.

21. Vaismoradi M, Turunen H, Bondas T. Content analysis and thematic analysis: Implications for conducting a qualitative descriptive study. Nurs Health Sci. 2013;15(3):398-405.

22. Braun V, Clarke V. Using thematic analysis in psychology. Qual Res Psychol. 2006;3:77-101.

23. Blumer H. Symbolic Interactionism. Englewood Cliffs, NJ: Prentice Hall; 1969.

24. Elizinga BM, Bremer JD. Are the neural substrates at memory the final common pathway in posttraumatic stress disorder (PTSD)? J Affect Disord. 2002:70:1-17.

25. Johnsen GE, Asbjørnsen AE. Consistent impaired verbal memory in PTSD: A meta-analysis. J Affect Disord. 2008;111:74-82.

26. Johnsen GE, Asbjørnsen AE. Verbal learning and memory impairments in posttraumatic stress disorder: The role of encoding strategies. Psychiatry Res. 2009;165(1-2):68-77.

27. Melinder A, Augusti EM, Matre M, Endrestad T. Associations between executive functions and long-term stress reactions after extreme trauma: A two-year follow-up of the Utøya survivors. J Psych Trauma. 2015;7(6):583-590.

28. Papadatou D, Metallinou O, Hatzichristou C, Pavlidi L. Supporting the bereaved child: teacher's perceptions and experiences in Greece. Mortality. 2002:7(3):324-339.

29. Dyregrov A, Dyregrov K, Idsoe T. Teachers' perceptions of their role facing children in grief. Emotion Behav Difficul. 2013:18(2): 125-134.

30. Charuvastra A, Cloitre M. Social bonds and posttraumatic stress disorder. Annu Rev Psychol. 2008;59:301-382.

31. Jacobsson G, Tysklind F, Werbart A. Young adults talk about their problems. Scan J Psychol. 2011;52(3):282-289.

32. Freud S. Mourning and melancholia. In: J Strachey, editor. The Standard Edition of the Complete Works of Sigmund Freud. London: Hogarth; $1917 / 1957$.

33. Lindeman, E. Symptomatology and management of acute grief. Am J Psychiatry. 1944;101:141-148.

34. Strobe M, Schut $H$. The dual process model of coping with bereavement: Rationale and description. Death Studies. 1999;23:197-224.

35. Stroebe M, Schut H, Stroebe W. Health outcomes of bereavement. Lancet. 2007;370:1960-1973.

36. Bugge KE, Haugstvedt KTS, Røkholt EG, Darbyshire P, Helseth S. Adolescent bereavement; embodied responses, coping and perceptions of a body awareness support program. J Clin Nurs. 2012; 21(15-16):2160-2169.

37. Kvernbekk T. Seeing in practice: a conceptual analysis. Scand J Educ Res. 2000;44(4):357-370. 
Psychology Research and Behavior Management

Dovepress

\section{Publish your work in this journal}

Psychology Research and Behavior Management is an international, peerreviewed, open access journal focusing on the science of psychology and its application in behavior management to develop improved outcomes in the clinical, educational, sports and business arenas. Specific topics covered include: Neuroscience, memory \& decision making; Behavior modification \& management; Clinical applications; Business \& sports performance management; Social and developmental studies; Animal studies. The manuscript management system is completely online and includes a quick and fair peer-review system. Visit http://www.dovepress. com/testimonials.php to read real quotes from published authors.

Submit your manuscript here: http://www.dovepress.com/psychology-research-and-behavior-management-journal 